\title{
La decolonización \\ del saber y el ser mapuche: \\ un caso de estudio al celebrarse \\ el bicentenario de la construcción de la República de Chile
}

\author{
Jorge Calbucura
}

Mid Sweden University, Östersund, Suecia. Email: jorge.calbucura@miun.se

Resumen: En el marco de la conmemoración del bicentenario se destaca una tendencia generalizada por la exaltación del bolivarismo, el nacionalismo y el indigenismo. Los tres temas evidencian una conmemoración que se caracteriza por la necesidad de recuperar la identidad o nacionalidad como instrumento de pertenencia y cohesión social. En particular en el marco de la llamada "exaltación del indigenismo" emerge la confrontación histórica entre pueblos originarios y el Estado republicano en América; esto a la luz de tres nociones, la identidad latinoamericana, el nacionalismo y el Estado-nación. En referencia a estas tres nociones y desde la perspectiva de la teoría de la matriz de poder colonial, el foco del análisis es "ser mapuche” en el contexto de la celebración del bicentenario en Chile.

Palabras clave: mapuche, bicentenario, social construcción, Estado-nación, matriz de poder colonial.

\section{The decolonisation of knowledge and the being a Mapuche: a case study in the commemoration of the bicentennial of the building of the Republic of Chile}

\begin{abstract}
In the commemoration of the bicentennial of the independence from Spanish rule in Latin America highlights a general tendency for the exaltation of bolivarianism, nationalism and indigenism. These three tendencies represent a commemoration that is characterised by the need to recuperate the identity or nationality as a tool for belonging and social cohesion. Specifically, within the framework of the "exaltation of indigenism" emerges the historic confrontation between native peoples and the Republican state in America, in the light of three notions: Latin American identity, nationalism and nationstate. In reference to these three concepts and from the perspective of the colonial matrix of power theory, the analysis focuses on "being Mapuche", that is, being indigenous people in Chile in the context of the commemoration of the bicentennial.
\end{abstract}

Key words: mapuche, bicentennial, social construction, nation - state, colonial matrix of power. 


\section{A descolonização do conhecimento e ser Mapuche: um estudo de caso em comemoração ao bicentenário da construção da República do Chile}

Resumo: Como parte da comemoração do bicentenário destaca uma tendência geral para a exaltação do bolivarismo, o nacionalismo eo indigenismo. Todos os três temas mostram uma comemoração que se caracteriza pela necessidade de recuperar a identidade ou a nacionalidade como um instrumento de pertença e de coesão social. Em especial, no âmbito da "exaltação do indianismo" emerge confronto histórico entre os povos e do Estado republicano na America; esta à luz de três noções, a identidade americana, o nacionalismo eo Estado - nação. Em referência a essas três noções e do ponto de vista da teoria da matriz de poder colonial o foco da análise é "ser Mapuche", no contexto da celebração do bicentenário do Chile.

Palavras-chave: Mapuche, bicentenário, construção social, a nação - Estado, matriz - o poder colonial.

\section{Introducción}

En América Latina en el marco de la conmemoración del bicentenario $^{1}$ se destaca una tendencia de "presentificación" de la historia, caracterizada por la exaltación del bolivarismo, el nacionalismo y el indigenismo. Dicha exacerbación se relaciona a un problema de la interpretación histórica del continente y evidencia la ausencia de una visión de sociedad, de comunidad, y sentido de pertenencia que lo relaciona a un problema de cohesión social. Ejemplos que ilustran dicha situación son el "bolivarismo"2 de Venezuela promovido por Hugo Chávez y el indigenismo "retro" de Bolivia, por Evo Morales.

$\mathrm{Al}$ igual que con motivo de la conmemoración del Quinto Centenario del "Descubrimiento de América" en 1992, que fue empañado por la irrupción de las protestas de las organizaciones indígenas la conmemoración del Bicentenario en América Latina desvela la preocupación de los intelectuales y políticos por la necesidad de recuperar la cohesión social.

En este caso la exaltación del bolivarismo, el latinoamericanismo, el nacionalismo y el indigenismo en América Latina emergen como expresiones políticas o culturales que expresan diferentes nociones de cohesión social y que ilustran una distancia de los valores y discursos dominantes. En perspectiva histórica contribuyen a estructurar un discurso alternativo que separa a segmentos sociales de los sectores tradicionalmente dominantes. Esta preocupación por la recuperación de referentes sociales, políticos y culturales no está exenta de complicaciones; el latinoamericanismo y el nacionalismo en los países de Latinoamérica; en su particular relación con los pueblos originarios es complejo.

Una de estas complicaciones alude al problema que el bicentenario 
se caracteriza por un nacionalismo potenciado por la izquierda ${ }^{3}$. Dife-

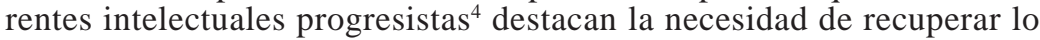
nacional como una forma de contrarrestar la presión del capital globalizado y como plataforma de lucha contra la transnacionalización de la cultura y la economía.

Desde los referentes latinoamericanismo y nacionalismo se enfatiza la fundación de las instituciones republicanas y los ideales democráticos de los principios de la independencia del Imperio español. Por otra parte; la emergencia de las republicas latinoamericanas se percibe como el resultado de la conquista y subyugación de los pueblos indígenas.

\section{Antecedentes Teóricos}

\section{La matriz de poder colonial}

De acuerdo con Mignolo (2009) la colonización de los pueblos indígenas al momento de la ocupación militar del territorio y por ende la subyugación de los pueblos originarios deviene en la imposición de la matriz de poder colonial. La que se materializa en tres esferas de poder: el control de la economía (apropiación de tierras y recursos naturales), el control de la autoridad (formas de gobierno, control militar) y el control del conocimiento y de la subjetividad (colonialidad del saber y del ser) que involucra toda la gama de producción de conocimiento.

Las relaciones de estas tres esferas, en la matriz colonial de poder se producen entre la “dominación material” (economía, autoridad, instituciones) y la “dominación epistémica.” De esta interrelación emerge la importancia del conocimiento en el control de la subjetividad, consecuentemente, en el control de la economía y la autoridad.

En esta línea de razonamiento la matriz colonial de poder genera el pensamiento (conocimiento) de la exterioridad: es decir, en el proceso de definir “el adentro” (humanidad, civilización, desarrollado, superior, heterosexual, blanco o blanca, cristiano o cristiana, europea o europeo, o criollo/mestizo/a de descendencia europea) en contraste con los clasificados/as como los de afuera (anthropos, bárbaros, primitivos, inferiores, homosexuales, lesbianas, indios).

A partir de esta situación de coexistencia en conflicto Mignolo (2005) ve la emergencia del pensamiento decolonial como pensamiento fronterizo donde la decolonialidad emerge en la exterioridad (en la frontera.) Generándose así la creación del afuera por el adentro. Una dinámica en una frontera en la que los dos lados no están en igualdad de condiciones. Y a partir de esas circunstancias "los de afuera" los que "han quedado fuera del juego" y de la participación en la toma de decisiones reclaman sus derechos epistémicos. 
En ambas situaciones se sugiere la existencia de una forma de dominación impuesta que subyuga y crea sujeto sobre el que se ejerce el poder. Al respecto Foucault (2005) puntualiza que una relación de poder solo puede articularse sobre la base de dos elementos; que el "otro" (aquel sobre el cual se ejerce el poder) sea completamente reconocido y mantenido hasta el final como una persona que actúa; y que, enfrentada a una relación de poder, pueda abrirse un campo entero de respuestas, reacciones, resultados e invenciones posibles. Es en este contexto donde la historia de resistencia de los pueblos indígenas proyecta una dimensión a la realidad política y social latinoamericana.

\section{El Estado-nación y la identidad nacional como producto de ingeniería simbólica}

La nación moderna se define sobre la base del principio de territorialidad; es decir representación geográfica. Desde esta perspectiva estado es territorio nacional el cual es la representación mental de un espacio geográfico, social y sociológico en la conciencia colectiva de una nación. La relación territorio y nación sugiere la idea de Estado, y consecuentemente la emergencia del paradigma nacionalista ${ }^{5}$.

El concepto estado en tanto personificación de nación y territorio indistintamente reconoce niveles locales y globales. Para tal propósito se destaca la interrelación sociedad, entorno geográfico e histórico. Estado se emplaza en el centro moral de una nación; definiendo el perfil del sentido de pertenencia e identidad. Nación define la extensión de lo que se considera como país de origen y nación sin país (Estado) de origen no es considerado nación.

Así, soberanía, ha devenido en concepto geográfico. Las proclamas de independencia de la revolución francesa y norteamericana inauguraron una nueva era en la representación simbólica de la nación o patria. La innovación mas destacada en el texto de las proclamas es la relación que se establece entre nación y estado. Categóricamente se determina potestad legal sobre los territorios definidos como inhabitados y bajo la jurisdicción de la soberanía estatal.

Esta fórmula jurídica ha servido de fundamento para configurar la representación geográfica simbólica en base a la cual se concibió la idea de declarar inhabitados los territorios indígenas en Norte y Sudamérica, afianzando de esta manera la relación territorio a nación y nación a estado. Por ejemplo en Argentina a la guerra contra los indígenas se le adjudicó el nombre "La Conquista del Desierto". Bajo esta representación simbólica que alude a la noción "free lands" (terra nullius) se legitimó la ocupación y usurpación por parte del Estado Argentino.

El nacionalismo ha devenido parte integral del discurso político durante el curso de los siglos XVIII y XIX, sirviendo como fundamento al desarrollo del proyecto de las formaciones de las republicas y de los esta- 
dos - nación. En el marco de este contexto la invención de la nación concibió la invención del espacio social; haciendo equivalente nación con territorio bajo jurisdicción estatal. El advenimiento de la nación como concepto político resultó en el proyecto de la "nacionalización de los pueblos", es decir, la integración de las naciones en un conglomerado social mediante su homogeneización lingüística y un sistema de educación único y centralizado. Este proceso también ha sido denominado como la operación intelectual de deshistorizar a los pueblos.

Överland (2000) destaca en su estudio que en la segunda mitad del siglo XIX al producirse la masiva radicación de inmigrantes -básicamente europeos- en Estados Unidos, las identidades nacionales de la mayor parte de los inmigrantes -como el caso de noruegos e italianos- no estaba desarrollada. No, hasta el momento de definirse como norteamericanos. El definirse norteamericano originó el fortalecimiento de una identidad dual; tanto con el país de origen, como con el país de adopción; -en este casoEstados Unidos. Teniendo como referencia el caso del estudio de Överland ${ }^{6}$ se pueden establecer paralelos con el caso de la invención de la identidad nacional en América Latina y Chile.

Estos dos casos ilustran el proceso de invención dual de identidad nacional. Ambos casos se fundamentan en la conciencia de ser protagonista activo en el proceso de creación de fronteras socioculturales, por ende la definición de la identidad nacional.

Devenir en "latinoamericano" -al igual que en el caso norteamericano- determina la articulación de un mecanismo de exclusión que se fundamenta en la aplicación del principio establecido por Överland7 "ningún tipo de consideración por los excluidos". En consideración a las referencias en los postulados enunciados por los fundadores (por ejemplo Simón Bolívar) de las repúblicas americanas se hace evidente que en las Américas históricamente el rol de "excluidos" les ha correspondido a los indígenas.

Ningún tipo de consideración por los excluidos, es el mecanismo de la ingeniería simbólica de la identidad dual nacional; es decir, su inclusión en la comunidad nacional imaginaria. Esto sobre la base de la idea de la fusión en el crisol (the melting pot) étnico nacional. El "crisol" latinoamericano consiste en internalizar que la fusión étnica opera sobre la base del referente cultural latino y la incorporación al proyecto de construcción la comunidad nacional imaginaria. Simbólicamente la fusión en el crisol étnico nacional es la operación de "desnacionalizar" a todo aquel que no se reconoce heredero de la tradición cultural anglosajona (en el caso norteamericano) o latinoamericana (en el caso de Sudamérica).

De acuerdo con Överland (2000) la doble identidad nacional particularmente en las Américas contempla una interrelación dinámica de tres mitos; el mito de la fundación "nosotros arribamos primero", el mito de la inmolación por la patria "los nuestros sacrificaron sus vidas en aras de la patria" y el mito de la asociación ideológica; "la conquista integró 


\section{a América en la historia universal, y en el occidente cristiano."}

La ingeniería simbólica como imaginario de la "doble identidad" integra dos esferas del conocimiento; la cultural y la política. Esta interrelación se materializa en la mezcla de la historia oficial con mitos e invenciones colectivas. Formando de esta manera una estructura imaginaria dinámica donde el "pasado" emerge como expresión simbólica de un destino colectivo, que responde a un proyecto continental y nacional emancipador y con proyecciones futuras y no a uno prediseñado en el pasado arcaico.

El presente estudio se ocupa de la confrontación histórica entre pueblos originarios y el Estado republicano en América en el marco de la conmemoración del bicentenario de la independencia del Imperio español. Este trabajo a la luz de tres conceptos; identidad latinoamericana, nacionalismo y Estado - nación, tiene como objetivo contribuir en el análisis desde la perspectiva de la teoría de la matriz de poder colonial. El foco del análisis se concentra en el "ser indigena mapuche" en el contexto de la celebración del bicentenario en Chile. El análisis del "ser mapuche" se desarrolla en contraste con el concepto "identidad nacional" y se concentra en la exploración de la interrelación del imaginario conformado por la historia oficial y los mitos colectivos. Para tal propósito se destaca la interrelación dinámica de tres mitos; el mito de la fundación, el mito de la inmolación por la patria y el mito de la asociación ideológica.

\section{La nación mapuche}

En el sur del continente americano existen unos 410 pueblos autóctonos que se diferencian entre sí. El pueblo mapuche que habita en la zona cordillerana-sur de Chile y Argentina, con aproximadamente un millón cuatrocientos mil miembros constituye uno de los grupos aborígenes más numeroso del continente, junto con Aymarás, Quechuas, Mayas, Cackchiqueles, Mixtecas, Nahuatles, Otomies, Pipiles, Quichés, Yacatecos y Zapatecos (Hernández, 1985:11).

En Chile los mapuches llegan a ser cerca de un millón, mientras que el resto se ubica en Argentina. En Chile residen mayoritariamente en la denominada Región de la Frontera, en las provincias de Bio-Bio, Arauco, Malleco, Cautín, Valdivia, Osorno, Llanquihue y Chiloé. La densidad más alta de población mapuche esta en la provincia de Malleco y Cautín, donde llegan a ser un $40 \%$ de la población total. Se estima que unos cien mil del total residen en los grandes centros urbanos de Santiago, Concepción, Valparaíso, Temuco y Valdivia. Hasta la década de los setenta la mayoría se concentraba en 2.060 "Comunidades Indígenas" (reducciones indígenas.) En la década del ochenta, la dictadura militar decretó la división de la tierra comunal en títulos de posesión individual; como consecuencia de tal medida las 2.060 Comunidades Indígenas se redujeron a 665. 
En Argentina los mapuches residen en las provincias de Neuquén, Rio Negro, Chubut, y Santa Cruz. En estas provincias constituyen un 30\% de la población total. Hasta la década del 80 se concentran en 32 Comunidades Indígenas.

\section{La autonomía territorial de los mapuches. Visión histórica}

A diferencia de lo sucedido con la mayoría de los pueblos indígenas del continente americano, las fuerzas militares del imperio español no lograron someter a los indígenas del sur de América. Después de decenios de sangrienta guerra entre mapuches y españoles, el 9 de enero de 1641, se pactó el cese de hostilidades; se firmó el Tratado de Paz de Quilín. Este acuerdo reconoció como límite sur de la unidad administrativa imperial de la Capitanía General de Chile, el río Bio-Bio. Se estableció que allí comenzaba la Araucanía. Ciento setenta años después, en 1811 en el Parlamento de Concepción en condiciones un poco más desventajosas para los mapuches los principios del Tratado de Paz de Quilín fueron ratificados por los representantes de la naciente República de Chile. De esta forma la Araucanía conservó su autonomía territorial durante 242 años.

Los mapuches del lado Argentino en alianza con otras tribus formalizan la autonomía de su territorio a partir de 1835, fecha en que forman la Confederación de Salinas Grandes. Bajo la dirección del Toki (jefe político y militar) Juan Calbucura ${ }^{8}$ se agruparon ranqueles, salineros, pampas, manzaneros, tehuelches y arribanos. Esta confederación controló el mayor territorio bajo dominio indígena en tiempos contemporáneos. Gracias al tratado de paz firmado entre el general Urquiza y el Toki Juan Calbucura la Confederación de Salinas Grandes conservó su autonomía territorial durante más de cuarenta años.

La guerra contra el pueblo mapuche es una de las guerras más larga de la historia. La agresión militar recorre algo más de tres siglos. Va desde la invasión de los españoles al territorio mapuche (Pedro de Valdivia 1541), hasta la "Conquista del Desierto" (1833-1881) ${ }^{9}$ en Argentina y la "Pacificación de la Araucanía" (1862-1883) ${ }^{10}$ en Chile. Históricamente, el punto central de beligerancia entre los mapuches, el Estado imperial español, el Estado republicano argentino y chileno ha sido la defensa de la tierra por los primeros y el afán de extender sus dominios por los últimos.

$\mathrm{Al}$ igual que el resto de los pueblos indígenas de América la población mapuche sufrió una drástica disminución en el curso de los últimos siglos. De acuerdo a la estimación de Hernández (1985:14) cuando comienza la invasión de los españoles, en el actual territorio chileno, la población mapuche alcanzaba la cifra cercana al millón de personas ${ }^{11}$. Tres décadas después eran reducidos a unos 600.000. Doscientos años después, durante la guerra de exterminio desatada por los gobiernos de Argentina y Chile el genocidio llegó a su punto cúlmine. Se estima que en Chile los indígenas sobrevivientes de la guerra no sobrepasaban 150.000. La estimación de Hernández es confirmada por los datos oficiales; en 1907 el Primer 
Censo Indígena reportó 107.000 mapuches en territorio chileno.

Hasta el momento en que el Estado republicano argentino y chileno no ejerció su soberanía sobre los territorios mapuches, la "cuestión indígena" fue un problema de carácter político-militar. Después del sometimiento militar y la relegación en reservas la "cuestión indígena" se transformó en un problema político-social. El Estado chileno y argentino han brindado un trato diferente a los mapuches en su calidad de vencidos de guerra. En el caso chileno, a ciento nueve años después de haber relegado a los mapuches en reducciones se puede constatar que el Estado no ha garantizado la existencia legal de la Comunidad Indígena. Por el contrario, el Estado chileno ha legislado ininterrumpidamente con el fin de fomentar la abolición del sistema de propiedad colectiva de la tierra. En el marco de este contexto se constata un arbitrario procedimiento legal que progresivamente inhabilita de sus derechos a aquellos que la ley reconoce como mapuches ${ }^{12}$. Situación similar no se observa en el caso argentino.

\section{El Estado - nación y la identidad nacional}

\section{El mito de la fundación}

Destaca el protagonismo de los conquistadores y colonizadores. Aquí se exaltan los relatos sobre "los descubrimientos," las primeras exploraciones, y las fundaciones de los enclaves coloniales. En Sudamérica el personaje central de esta gesta es Cristóbal Colón y una amplia gama de "descubridores y fundadores de ciudades."

En las Américas el mito de la fundación ha moldeado la identidad de los países mediante la síntesis de un pasado elaborado de una única y exclusiva fusión. Es sobre la base de esta premisa que se genera la versión de uno de los temas más complicados de la historiografía de las Américas, el mito de la fundación "nosotros arribamos primero." Lo que en términos empíricos refiere la expansión fronteriza, el desplazamiento, emplazamiento, transición y alteración de las fronteras socio-culturales.

La teoría de "expansión fronteriza” en las Américas considera dos modelos de apropiación de territorios o expansión fronteriza; la hispana y la anglosajona. De acuerdo con Turner (1893) en el caso anglosajón la "expansión fronteriza" se caracteriza por la apropiación de "free lands" (terra nullius). Sobre la base de este razonamiento Bolton (1932) desarrolla la idea que "expansión fronteriza" también es un proceso de incorporación territorial sobre la base del desplazamiento de las fronteras socio-culturales. De acuerdo con esta definición, el desplazamiento de las fronteras determinó que los grupos indígenas sedentarios fueron rápidamente incorporados a la jurisdicción socio-cultural, y sin embargo, no sucedió lo mismo con los grupos indígenas nómades. La resistencia de estos grupos al desplazamiento de las fronteras socio-culturales impone la necesidad de diferenciar entre fronteras militares y socio-culturales. 
Nuestro caso de estudio; se enmarca en el estudio de la resistencia de los indígenas mapuche de Chile (grupos indígenas sedentario) al desplazamiento de las fronteras socio-culturales del Imperio Español. Consecuentemente el foco de nuestro análisis se concentra en la convivencia interétnica a partir de la existencia de fronteras militares, así como el desplazamiento y alteración de la jurisdicción socio-cultural. El Imperio español y la nación mapuche convivieron en torno a la frontera militar conocida como la frontera del río Bío Bío que entre 1642 hasta 1883 delimitó el territorio mapuche del español en el territorio de la actual republica de Chile.

De acuerdo con Turner (1913) la diferencia entre Norteamérica y Europa radica en la existencia de una frontera, donde la lucha de los pioneros contra la naturaleza hostil contribuye al desarrollo de la "nueva sociedad". El continuo avance de colonos sobre "la tierra de nadie" ("no man's land") del oeste; forja la mentalidad de un pueblo en expansión, en busca de nuevas oportunidades y que adaptándose a continuos cambios cimienta el desarrollo del sistema democrático norteamericano. Sobre la base de la misma referencia Webb (1986) acuña el concepto del "gran y continuo avance" que ilustra la emergencia de un "este" civilizado y un "oeste" no colonizado. De acuerdo con el autor este modelo ilustra el surgimiento de las repúblicas de Canadá, Australia, Sud África y Nueva Zelandia.

Los estudios sobre la apropiación de territorios o expansión fronteriza; hispana se inicia con Bolton (1917), quien en el marco de la teoría del desplazamiento de las fronteras socio-culturales destaca la vigencia del modelo; "borderlands" como característico de la expansión hispana. En este caso Bolton a diferencia de Turner no ve la frontera como un punto de acceso de un territorio libre, sino un territorio poblado por indígenas. En este caso, concibe la frontera como un espacio sociopolítico donde coexisten instituciones y relaciones sociales; por lo que ésta pasa a ser un punto de desplazamiento de límites socio-culturales; esto gracias a la gestión de los agentes religiosos y civilizadores. La tesis de Bolton ha inspirado un sinnúmero de investigaciones concentradas en la influencia de los agentes protagonistas en la expansión fronteriza. En esta misma línea argumental Mackendrick (1957) desarrolla el concepto "hombre fronterizo" y la "ciudad-estado" que en este caso los destaca en el rol de agentes portadores de la civilización y el progreso. Las misiones religiosas se destacan como una de las instituciones más importantes en este proceso de expansión sociocultural y en segundo lugar se destaca el rol de los presidios, las milicias y los asentamientos de los colonos europeos. De esta forma la noción de la “expansión fronteriza” no es tan solo un proceso de apropiación de territorio sino que un proyecto de desplazamiento de las fronteras socio-culturales; con lo cual se alude a la integración de los no civilizados al mundo occidental y a la modernidad.

En el caso de Chile la particular situación de convivencia interétnica a partir de la existencia de una frontera militar, así como la resistencia de la nación mapuche al desplazamiento de la frontera socio-cultural hispana a devenido en diferentes interpretaciones. 
La versión oficial de la historia de Chile destaca la idea de la expansión fronteriza chilena a la modalidad norteamericano; del "gran y continuo avance.” En este marco de razonamiento el historiador Villalobos (1982) ha contribuido con una interpretación adicional a la noción "desplazamiento de la frontera socio-cultural hispana.” Villalobos reconoce la existencia de población indígena (mapuche) en forma de conglomerados nómades, con la particularidad que -de acuerdo a su descripción- se trataba de grupos sociales en un perpetuo nivel de descomposición y anomia social (víctimas del alcoholismo.) De acuerdo con Villalobos, bajo estas circunstancias no existen antecedentes que acrediten la existencia de una jurisdicción sociocultural, ni mucho menos una modalidad de ejercicio soberano por parte de los indígenas mapuche sobre un territorio. Desde este punto de vista el territorio mapuche es considerado "la tierra de nadie" -al igual que en el caso norteamericano- abierto al avance de los colonos.

Por otra parte, este caso de existencia de frontera militar, así como la resistencia de la nación mapuche al desplazamiento de la frontera sociocultural da paso a la posibilidad de interpretación desde una perspectiva decolonial. En este caso, importante de destacar es el protagonismo indígena en los límites de la interacción socio-cultural y en particular el rol de las instituciones de los pueblos originarios. Un antecedente importante de considerar es que en el territorio americano bajo la administración por el Imperio español las naciones indígenas en condición de súbitos de la corona mantuvieron su estructura social y político administrativa. Lo que los habilitó como interlocutores con los representantes de la Colonia española; así como evidencia el proceso de adaptación a que se vieron sometidas las estructuras políticas de las naciones indígenas como efecto de las condiciones impuestas.

Tal como se indica anteriormente, el territorio ubicado al sur del río Bio Bio y al norte del río Toltén, no pudo ser colonizado por el Imperio Español. Así surgió a comienzos del siglo XVII una frontera hispano-indígena (y posteriormente mapuche - chilena y argentina) eminentemente militar. Al respecto; en el caso mapuche vale destacar los cónclaves denominados "parlamentos" que celebraban españoles y las entidades territoriales mapuche llamadas Futamapu. Importante de destacar es que la modalidad de convocatoria, así como el procedimiento protocolar estaba determinada a la usanza mapuche. Procedimiento que con el tiempo los españoles integraron totalmente. Particularmente el tema de los "parlamentos" celebrados entre españoles y mapuche durante más de dos siglos, son el ejemplo de la vigencia y existencia de los límites de la interacción socio-cultural.

La evidencia de esta relación se materializa en los Tratados suscritos entre la corona de España y la nación Mapuche. La secuencia de tratados entre la nación mapuche y la Corona española es larga y comienza con el Parlamento de Killin, el 6 de Enero de 1641 y termina con el Parlamento General de Negrete ${ }^{13}$ del 3 - 5 de Marzo de 1803.

En total se trata de 36 Tratados Internacionales sancionado entre 
mapuche y la Corona Española ${ }^{14}$. De lo cual vale destacar que desde Parlamento de Killin, de 1641 hasta el Parlamento General de Negrete de 1803, la corona española reconoce la inviolabilidad del territorio y la autodeterminación mapuche; así como el compromiso de defensa mutua ante la agresión extranjera. En similares términos la naciente Republica de Chile suscribe en 1825 el Tratado de Tapihue con los representantes políticos mapuche $^{15}$; un tratado cuyo texto destaca que la nueva república chilena, establece que no violará la mutua frontera ${ }^{16}$. Este tratado establece que el Río Bio-Bio es la frontera entre Chile y Ragko-Mapu ${ }^{17}$ o Nación Mapuche. Como antecedente complementario vale destacar que la Constitución política de 1833 establece que la jurisdicción territorial de la Republica Chile va desde las provincias de Coquimbo hasta Concepción. Es decir al norte del Río Bio-Bio.

Treinta y seis Tratados suscritos con la Corona española y uno con la republica de Chile así como toda la operación de confinamiento de población mapuche en reservas indígenas son antecedentes que evidencian una convivencia fronteriza entre tres naciones soberanas e ilustran esta relación desde la perspectiva de “borderlands” y el desplazamiento de la frontera socio-cultural.

El protagonismo indígena en los límites de la interacción socio-cultural fronteriza no ha merecido la atención de los cientistas sociales particularmente en lo que respecta la expansión fronteriza, el desplazamiento, emplazamiento, transición y alteración de las fronteras socio-culturales.

\section{El mito de la inmolación en aras de la patria}

Cultural y políticamente allana la integración en la comunidad nacional imaginaria exaltando la importancia del sacrificio o la inmolación en aras de la patria. Aquí se materializa como vía de inclusión en el colectivo imaginario de aquellos que no fueron beneficiados con la herencia biológica-cultural latina. La patria (estado-nación) suministra guerras e inmolarse por la patria es la máxima expresión de lealtad por el colectivo nacional imaginario. En Latinoamérica; la participación en las guerras de independencia, guerras civiles o guerras interestatales otorgan certificados de lealtad a la patria. La galería de los héroes americanos no solo incluye individuos, sino que destaca la participación de grupos étnicos.

Al respecto un antecedente ilustrativo lo aporta Estados Unidos con la reciente inclusión de la nación navajo en la galería de honor de los patriotas norteamericanos. Esto gracias a la participación de los indígenas navajos en la Segunda Guerra Mundial en un equipo de 75 radio operadores quienes participaron como telegrafistas transcribiendo comunicaciones cifradas en lengua navaja. El film "código indescifrable"18 (Unbreakable Code) relata esta gesta patriótica; así como simbólicamente ilustra esta integración en la comunidad nacional imaginaria.

En el caso chileno es difícil encontrar representantes de los pueblos 
originarios como protagonistas en las gestas bélicas de la patria imaginaria. Más bien todos los antecedentes indican lo contrario; en el caso especifico de la nación mapuche; estos se destacan por activamente haber combatido en contra de la fundación de la Republica de Chile.

La razón por la que los indígenas mapuche no ocupan un lugar en la comunidad imaginaria chilena se debe al hecho que fueron aliados militares de los españoles. Lo que a su vez tiene que ver con una historia de doscientos años de relaciones fronterizas entre dos entidades soberanas; la mapuche y la española. Tal como se destaca más arriba en más de doscientos años de relaciones fronterizas se suscribieron 36 Tratados. Los textos de los Tratados suscritos entre mapuche y la Corona Española destacan tres elementos centrales; la inviolabilidad del territorio, la autodeterminación de la nación mapuche y el compromiso de defensa mutua ante la agresión extranjera.

La guerra de independencia que libraron los chilenos contra los españoles fue en su absoluta mayoría protagonizada por criollos (españoles nacidos en las colonias del imperio) y mestizos (generalmente descendiente de padre español y madre indígena). La población indígena; en particular la mapuche masivamente combatió al lado de las fuerzas militares españolas.

Desde el punto de vista del mito de la inmolación en aras de la patria en Chile en siete oportunidades se han generado la posibilidad de ocupar un lugar en la galería de los héroes y mártires del imaginario nacional. Chile ha participado en tres guerras interestatales ${ }^{19}$ (contra España - mapuche y en dos ocasiones contra la confederación Perú - Bolivia), tres guerras civiles $^{20}$ y una de anexión territorial y limpieza étnica (contra nación mapuche ${ }^{21}$. Del total de siete conflictos armados en que el estado de Chile se ha visto involucrado, en dos de ellos las fuerzas militares de la nación mapuche han participado activamente como adversarios.

El primer caso tiene que ver con la activa participación de los mapuche al lado de las tropas del Imperio español. El 5 de Abril de 1818 las fuerzas republicanas chilenas en la batalla de Maipú derrotan a las fuerzas militares españolas. Los españoles reorganizaron sus fuerzas militares replegándose al territorio mapuche (al sur del río Bío Bío) y con el apoyo mayoritario de la nación mapuche inician operaciones militares en contra de las fuerzas militares chilenas. Entre 1819 - 1824 se desarrolla una guerra total entre españoles y su aliado mapuche contra las fuerzas militares chilenas. El contingente militar mapuche a disposición de las tropas españolas superaba los 6000 guerreros ${ }^{22}$. En 1824 las tropas españolas son derrotadas y un año mas tarde El lonko (jefe político) mapuche Francisco Mariluan suscribe con el gobierno de Chile, representado por el presidente de la república Ramón Freire; el Tratado de Tapihue.

Sin embargo, dos décadas después que el Estado chileno firma un acuerdo de paz con la nación mapuche y reconoce la autonomía de su terri- 
torio, el 2 de julio de 1852 dicta la ley "Los territorios mapuches deberán anexarse al Estado de Chile"23. Esta ley es conocida como la ley más insólita de Chile, ya que es una legislación extraterritorial; a aplicar en territorios fuera de la jurisdicción territorial chilena ${ }^{24}$. A partir de entonces se inicia la agresión, bajo la denominación "Pacificación de la Araucanía" que culmina con la ocupación del territorio mapuche y una campaña de limpieza étnica.

Los territorios conquistados se declararon terra nullius, y el Estado chileno procedió a la anexión de millones de hectáreas, que posteriormente se concedieron los colonos chilenos y europeos. Para fijar la residencia indígena prisioneros de guerra se formó una Comisión Radicadora con la tarea de asentarlos en un sistema de reservas indígenas. Entre 1884 y 1929 se entregaron 3 mil 78 títulos de propiedad, correspondientes a 475 mil 194 hectáreas, destinadas a 77 mil 751 personas.

De acuerdo con estos antecedentes y en una perspectiva histórica es posible de constatar que territorio-nación y nación-territorio son nociones intercambiables. Tanto la situación de autonomía territorial mapuche en el borde del Imperio español como la ocupación y anexión del territorio mapuche al estado de Chile evidencian que el territorio es susceptible a adoptar diferentes cualidades dependiendo de la jurisdicción institucional dominante.

El problema de la historia oficial chilena es como situar a los indígenas mapuche en el imaginario nacional; ya que no existen antecedentes que evidencien su sacrificio o inmolación por la patria. No es casualidad que la historia oficial destaque a los mapuche como los que resistieron militarmente los intentos de conquista española, con lo cual los integra en el imaginario nacional como los precursores de la lucha por la independencia de Chile del yugo colonial español ${ }^{25}$.

\section{El mito de la asociación ideológica}

El tercer mito en la agenda de inclusiones y exclusiones articula el carácter cultural y político de la noción América Latina que enfatiza como la conquista y colonización española derivó en la integración del continente al mundo occidental y cristiano.

La identidad latinoamericana y el nacionalismo en los países de Latinoamérica interrelaciona la idea del proyecto modernista y es el antecedente ideológico que confiere a ambas nociones un pasado y destino colectivo, que responde a un proyecto continental y nacional emancipador con proyecciones futuras y no a uno prediseñado en el pasado. Una clara alusión a deslegitimar el pasado indígena.

Desde esta perspectiva la identidad latinoamericana y el nacionalismo interrelaciona el mito de la asociación ideológica con la idea del pensamiento moderno y con la noción de progreso hacia una cultura racional. Al 
respecto; de acuerdo con Villoro (1998) la idea de modernidad emerge del concepto de la aceptación de una razón universal y única, igual en todos los hombres y en toda época. Una cultura conforme a la razón; la occidental, de raíces griegas y cristianas; las demás tienen valor como estadios en evolución hacia esa cultura superior.

\section{¿Latinoamérica, Hispanoamérica o Iberoamérica?}

Los sucesos de hace dos siglos iniciaron la independencia de la América española y dieron paso al surgimiento de las repúblicas hispanas en Sudamérica. Este proceso que se inició en 1809 y culmina en 1898 cuando España pierde ante USA el control de sus últimas colonias transoceánicas (Cuba, Puerto Rico, Filipinas y las Indias orientales.)

El concepto Ibero América ${ }^{26}$ es una imposición colonial que abarca a sus antiguos colonizadores en un bloque donde el 90\% de sus habitantes reside en las Américas. El concepto de Ibero América nació para expresar a las naciones hispanoamericanas más Brasil, pero con el tiempo se ha ido extendiendo hasta integrar a España y Portugal. Ibero América se gestó hace dos siglos cuando en 1808 las monarquías de Portugal y España, fueron ocupadas por Francia bajo el liderazgo de Napoleón Bonaparte. Esta situación que se inicia en 1810 y que culminó 165 años después con la independencia de las repúblicas hispano-hablantes del África y de Timor. Esto generó un radical cambio que culmina con la gestación de una treintena de nuevos Estados.

La conformación de las nuevas repúblicas contó con la activa participación de Gran Bretaña. Por un lado sus tropas ayudaron a la independencia de España y Portugal en contra de Francia y por otro lado brindaron apoyo a los hispanoamericanos de las colonias españolas en su lucha por la independencia de España. Así cuando Imperio español y portugués se libran de la ocupación francesa; pierden la posesión de sus colonias y confrontan el surgimiento de las nuevas republicas hispanoamericanas.

América Latina es un concepto que nació medio siglo después de la creación de las republicas americanas de Sud y Centro América a inicios del siglo XIX. La nueva denominación se acuña a partir de 1861 cuando el segundo imperio francés apoyado por fuerzas españolas, británicas y belgas invadió México -entonces- mayor y más rico territorio hispanoamericano. Francia, en orden de justificar y legitimar sus pretensiones geopolíticas, inventó al término de América Latina ${ }^{27}$, con lo cual pretendía legitimarse como regente de las nuevas repúblicas de sud y centro americanas que hablaban lenguas latinas (francés, español y portugués.) Este concepto fue mantenido por Londres y Washington quienes, así, debilitaron las pretensiones de influencia del ex Imperio Español sobre sus antiguos dominios.

América Latina, además de ser un concepto creado a mediados del siglo XIX por Francia para justificar la conquista de los territorios ameri- 
canos, siempre ha sido un concepto equívoco ya que por ejemplo; excluye a lo africano, indígena ${ }^{28}$ e ibérico.

La emergencia de las republicas latinoamericanas y la disolución del imperio español se produce en los umbrales del auge de la modernidad. Desde allí que las independencias de las colonias americanas forman parte de una reorganización del proyecto de la civilización occidental y el advenimiento del modernismo en el continente americano.

La identidad latinoamericana refiere a una conciencia continental y generalizada de lucha por la Independencia y en contra del Imperio español. La identidad latinoamericana se traduce en la conciencia de pertenencia a una comunidad más amplia, con un idioma común, una religión y bases culturales. En este contexto se destacan la fundación de las instituciones republicanas y los ideales democráticos de los principios de la independencia del sistema político colonial.

Es desde esta perspectiva que el nacionalismo en los países de Latinoamérica es inducido por el sentimiento latinoamericanista, en tensión con su opuesto, el nacionalismo. El sentimiento nacionalista se manifiesta en el fracaso de una revolución continental y que derivó en la subdivisión del continente, en enclaves de las oligarquías locales.

En el marco del el mito de la asociación ideológica emerge el tema de la identidad continental o nacional inspirada en la idea occidental que interrelaciona dos conceptos; Estado y nación. El mito de la asociación ideológica forzosamente pretende hacer coincidir Estado con una nación. Tal como Maldonado (2008) lo destaca; la idea del Estado nación es propia del pensamiento moderno.

La idea de nación emerge de dos tradiciones de pensamiento. Por una parte, de la tradición francesa heredera de la revolución francesa, que ve en la nación a una entidad política conformada por ley y por ciudadanos iguales. La nación francesa de la época napoleónica, la nación es una comunidad política constituida con posterioridad al Estado. La otra definición corresponde a la tradición romántica alemana que ve una nación en la existencia de una comunidad cultural, una misma lengua y un origen étnico común. Según La tradición alemana señala la existencia a priori de la nación como fundamento necesario de un Estado. La idea de modernidad emerge del concepto de la aceptación de una razón universal y única. En el marco de esta interrelación se representa el Estado-nación como una construcción racional, asentado en una supuesta homogeneidad étnica, lingüística y cultural.

En América Latina, el Estado surgió a partir de la importación del modelo político europeo y la idea de "nación” se materializa en el concepto del "crisol étnico” el cual supone la existencia, de una nación con ciudadanos iguales y sin distinciones étnico-culturales, que conviven en el marco del Estado. Tal como lo puntualiza Maldonado (2008) es necesario consi- 
derar que un Estado no es lo mismo que una nación y el Estado es, por definición, una entidad de carácter política. Considerar equivalentes ambos conceptos implica una contradicción ya que excluye el considerar a la nación como una entidad substancialmente cultural ${ }^{29}$. De acuerdo con Villoro $^{30}$ (1998) asumir que Estado y nación constituyen una unidad natural, implica ignorar que tanto Estado como nación responden a procesos distintos de formación. Nación no siempre estuvo ligada a Estado, y que tal noción, anterior a la época moderna, no involucraba el concepto de soberanía política. Muchas naciones podían coexistir bajo el mismo imperio o reino sin más vínculo político entre ellas que el vasallaje a un soberano común. Tal es el caso de la nación mapuche y su relación con el Imperio Español, como anteriormente hemos referido.

Estableciendo la distinción de nación en sentido político y en sentido cultural Maldonado (2008) establece una diferencia entre naciones históricas (o tradicionales) y naciones modernas (o proyectadas.) Siguiendo esta distinción cabe señalar que los pueblos indígenas, tienden a asumirse como naciones históricas y que el mito de la asociación ideológica latinoamericana reivindica asumir la noción de nación moderna.

Desde el punto de vista de la teoría decolonial y en particular desde la perspectiva del conocimiento y de la subjetividad (colonialidad del saber y del ser) es importante de considerar esta distinción.

Al respecto una situación común es como se genera ásperas reacciones, cuando las organizaciones representativas de los pueblos originarios en el contexto político, académico y cultural latinoamericano- usan el concepto “nación indígena”. En referencia al postulado de colonialidad del saber y del ser es necesario destacar en este caso se refiere a la connotación cultural (histórica) del término "nación" y no al significado moderno del mismo. Las organizaciones representativas de los pueblos indígenas le asignan al concepto "nación" un uso político; como expresión de autoafirmación identitaria. Esto en el propósito de obtener reconocimiento político a su existencia dentro del Estado nacional. Desde una lógica moderna el concepto "nación" genera suspicacias ya que se deduce que los indígenas propugnan la secesión del Estado-nación para constituir -por ejemplo- un Estado-nación mapuche.

\section{Conclusiones y comentarios finales}

El foco del análisis de este articulo sobre la confrontación histórica entre pueblos originarios y el Estado republicano en América en el marco de la conmemoración del bicentenario de la independencia del Imperio español interrelaciona tres conceptos; identidad latinoamericana, nacionalismo y Estado - nación, desde la perspectiva de la teoría de la matriz de poder colonial. El "ser indigena mapuche" en el contexto de la celebración del bicentenario en Chile se destacó como relevante en la exploración de la interrelación del imaginario nacional conformado por la historia oficial y 
los mitos colectivos. Para tal propósito se destacó la interacción dinámica de tres mitos; el mito de la fundación, el mito de la inmolación por la patria y el mito de la asociación ideológica.

El punto de partida de nuestro caso de estudio; se enmarcó en el estudio de la resistencia de los indígenas mapuche de Chile al desplazamiento de las fronteras socio-culturales del Imperio Español. El análisis se concentró en la convivencia interétnica a partir de la existencia de fronteras militares, así como el desplazamiento y alteración de la jurisdicción sociocultural española y mapuche. Se destaca como antecedente central el hecho que el Imperio español y la nación mapuche convivieron en los márgenes de una frontera militar conocida como la frontera del río Bío Bío durante 242 años.

La evidencia de esta relación se materializa en los Tratados suscritos entre la corona de España y la nación Mapuche. En total se trata de 36 Tratados sancionado entre mapuche y la Corona Española

En el caso de Chile la existencia de una frontera militar, así como la resistencia de la nación mapuche al desplazamiento de la frontera sociocultural hispana se interpreta de dos maneras. La versión oficial de la historia de Chile a pesar de reconoce la existencia de población indígena (mapuche) en dichos territorios; destaca la idea de la expansión fronteriza chilena a la modalidad norteamericano; del "gran y continuo avance." Con lo cual sugiere la idea de la existencia de una "tierra de nadie" abierta al avance de los colonos. El antecedente de la historia oficial que avala este postulado destaca que la sociedad mapuche consistía en grupos sociales en descomposición y anomia social. Lo cual alude el demandar la potestad del vínculo territorio y nación en función de legitimar la vigencia de un mecanismo de homogenización.

La segunda versión -en referencia a la teoría de la decolonialidaddestaca la existencia de frontera militar, así como la resistencia de la nación mapuche al desplazamiento de la frontera socio-cultural. Así se destaca el protagonismo indígena en los límites de la interacción socio-cultural y en particular el rol de las instituciones de los pueblos originarios como evidencia el proceso de adaptación a que se vieron sometidas las estructuras políticas de las naciones indígenas como efecto de las condiciones impuestas.

En el marco de este contexto se destaca la relación territorio-nación y nación-territorio y su condición de nociones intercambiables. Tanto la situación de autonomía territorial mapuche en el borde del Imperio español como la ocupación y anexión del territorio mapuche al estado de Chile evidencian que el territorio es susceptible a adoptar diferentes cualidades dependiendo de la jurisdicción institucional dominante. Situación que fundamenta el análisis del concepto estado - nación y identidad nacional como producto de la ingeniería simbólica.

Desde la perspectiva decolonial es posible destacar que la inven- 
ción de la nación en el caso chileno y en referencia a la historia oficial y los mitos colectivos deviene en un proceso de deshistorización de la nación mapuche en el propósito de definir el perfil de pertenencia e identidad nacional.

Una interpretación desde la perspectiva de la teoría de la decolonización; la historia mapuche y chilena comienza cuando se introduce la imposición de la matriz de poder colonial. La colonización de la nación mapuche y el rol de colonizador de la nación chilena se materializa al momento de la ocupación militar del territorio mapuche y por ende la subyugación de la nación mapuche en las tres esferas de poder: el control de la economía (el confinamiento de la población en un sistema de reservas indígenas), el control de la autoridad (abolición del poder formal de las autoridades tradicionales mapuche y control militar en las áreas de las reservas indígenas.)

Estos dos antecedentes nos permiten establecer la relación de estas dos esferas de la matriz colonial y su conexión con el control del conocimiento y de la subjetividad. En este particular contexto emerge como un antecedente en la exploración de la noción "colonialidad" en el terreno de la geo-política del conocimiento. Desde esta perspectiva el "saber y el ser mapuche" es parte del proceso de la invención ingeniería simbólica donde la invención del espacio social y su equivalente; nación-territorio y jurisdicción estatal es central y determinante. 


\section{Notas}

${ }^{1}$ El bicentenario de América Latina; en 2009 se celebraron los bicentenarios de las independencias de Bolivia y Ecuador y en el 2010 se conmemoran los de Venezuela, Argentina, Colombia, México y Chile.

${ }^{2}$ El bolivarianismo es una corriente de pensamiento político basada en la obra de Simón Bolívar, que une el Republicanismo Cívico-Humanista y el socialismo marxista; de tal integración emerge el denominado socialismo del siglo XXI. Dicho proyecto es promovido por la alianza de Naciones Bolivarianas (Bolivia, Colombia, Ecuador, Panamá, Perú y Venezuela.) La ideología bolivariana se basa en los escritos de Bolívar que redactó durante la lucha de independencia contra el Imperio español. Los documento más importantes son la Carta de Jamaica, el Discurso de Angostura y el Manifiesto de Cartagena. De ellos se destaca la idea del derecho a la educación pública gratuita y obligatoria, el evitar la intromisión extranjera en las naciones americanas así como la dominación económica de las potencias europeas. Propone, también la integración energética, económica y política de los países de Latinoamérica.

${ }^{3}$ Ejemplo de nacionalismo de izquierda es el Partido Socialista de Chile, con un programa político latinoamericanista y antiimperialista. El auge del sentimiento latinoamericano se materializa en la década de los sesenta y setenta, entonces se percibe a Estados Unidos como el enemigo, ya sea como agresor o aliado de las oligarquías nativas.

${ }^{4}$ Rojo (2005) Como bandera de lucha contra la transnacionalización de la cultura y la economía nacional.

${ }^{5}$ Para la discusión del tema ver William \& Smith, (1983); Dietz, (1989); Anderson, (1983)

${ }^{6}$ Ibid

${ }^{7}$ Ibid

${ }^{8}$ En la ortografía mapuche no existe la letra C y B, motivo por el cual diversos autores han transcrito este nombre en forma diferente. En todos los casos se refiere a la misma persona. Kalfukura: Julio Verne; Calvukura: Guevara (1913); Calfucura: Yunque (1956); Calvucurá: Zeballos (1890); Calbucura: Bengoa (1985). Calfu: azul, Cura: piedra. Calfucura: piedra azul.

${ }^{9} 1833$ marzo 22. se inicia la campaña militar de la "Conquista del Desierto," tres ejércitos invaden la pampa. El primero desde Chile al mando del general Bulnes, el segundo desde Mendoza y Córdoba comandado por los generales Aldao y José Ruiz Huidobro y el tercero desde Buenos Aires al mando de Rosas. La expedición fracasa; el cacique de los ranqueles, Yanquetruz derrota al ejército comandado por José Ruiz Huidobro. - 1881. Las tropas de Confederación de Salinas Grandes son derrotadas. El ejercito argentino ocupa la Patagonia. - 1881 julio 28. El presidente de la República de Chile Anibal Pinto firma el tratado en el cual se establece que el Estado chileno renuncia a sus derechos históricos sobre la Patagonia y que los límites entre ambos países son la Cordillera de los Andes. La Patagonia pasa a propiedad de la República Argentina. El gobierno argentino toma posesión sobre 41.555.700 hectáreas. - 1885 mayo 5. Namuncurá, sucesor de Juan Calbucura formalmente se rinde al general Winter, "Gobernador de la Patagonia". 
${ }^{10} 1862$ Fundación de Mulchén y Lebu, el ejército chileno inicia el avance al sur del rio Bío Bío. 1883 enero 1. Derrota del Toqui Epulef. El ejército chileno ocupa militarmente la Araucanía. El Estado chileno toma posesión de un territorio cercano a 10.000.000 de hectáreas.

${ }^{11}$ Esta cifra es corroborada por Hidalgo (1973) quien basa su estimación en un detallado estudio de los cronistas de la primera etapa de la conquista. Según la opinión de ciertos investigadores la estimación de una población cercana al millón es considerada como "estimación optimista." Sobre esta discución ver Solís (1981).

${ }^{12}$ Sobre la discusión ver Calbucura (2008)

${ }^{13}$ Reconoce la soberanía de los mapuche sobre el territorio que corre desde el río Bio-Bio hasta el Tolten.

${ }^{14}$ Gavilán (2002).

${ }^{15}$ La firma del Tratado es precedida por promulgación la ley del 27 de Octubre de 1823 que reconoce los Tratados o Parlamentos como norma de derecho internacional valido entre Chile y los Territorios de Arauco. Mas adelante el 10 de enero de 1825, Ramón Freire firma el Tratado de Tapihue.

${ }^{16}$ Del texto original "Haciendo memoria de los robos escandalosos que antiguamente se hacían de una y otra parte, queda desde luego establecido, que el Chileno que pase a robar á la tierra y sea aprehendido, será castigado por el Cacique bajo cuyo poder cayere, así como lo será con arreglo a las leyes del país el natural que se pillase en robos de este lado del Bío bío que es la línea divisoria de estos nuevos aliados hermanos".

${ }^{17}$ Del mapudungun "ragko" que significa tierra gredosa, transformada en el vocablo "Arauco" por los españoles. Con este término denominaron el territorio mapuche al sur del del Bio Bio.

${ }^{18}$ Windtalkers (2002) dirigida por John Woo.

${ }^{19}$ Guerra de la Independencia de Chile (contra España - nación mapuche) (1813-1826) Guerra contra la Confederación Perú-Boliviana (1836-1839) Guerra del Pacífico (18791884.) Contra la Confederación Perú-Boliviana.

${ }^{20}$ Guerra civil 1829-1830; Guerra civil 1851; Guerra civil 1891.

${ }^{21}$ Ocupación de la Araucanía (1861-1883) o Pacificación de la Araucanía contra la nación mapuche.

${ }^{22}$ Esa es la cantidad que comandaba el jefe militar mapuche Mañil. También hay que considerar la participación de otros líderes militares como los de las localidades de Arauco, Tubul, Boroa, Imperial y Lebu.

${ }^{23}$ Durante el Gobierno de Manuel Montt. A esta ley le sigue la de 4 de diciembre de 1866 que dicta la fundación de la provincia de Arauco en el corazón del territorio mapuche.

${ }^{24}$ Art.1.-Crease una nueva Provincia con el nombre de provincia de Arauco; que demarcará 
sus límites los Territorios de Indígenas ubicados al Sur del Rio Bio-Bio. Art.3.-Para todos los efectos de esta nueva ley queda al arbitrio del supremo gobierno anexar todo cuanto a bien del Presidente de la Republica lo requiera.

${ }^{25}$ Sobre el tema ver Calbucura (2005).

${ }^{26}$ Es la América de habla castellana y portuguesa que se ha ampliado hasta integrar a sus ex colonizadores y a las antiguas colonias; como: Filipinas, Guinea Ecuatorial, y los Países Africanos de Lengua Oficial Portuguesa (PALOP) y Timor.

${ }^{27}$ La palabra 'latina' se refiere a un pueblo originario del centro de Italia (Latium o Lacio) o a la lengua que hablaban los romanos.

${ }^{28} \mathrm{Al}$ momento en que Francia creó el término ‘América Latina’ la mayoría de la población de México, Guatemala, Paraguay y de los Andes Centrales hablaba lenguas amerindias. Hoy los amerindios utilizan la palabra ‘Abya Yala’ para designar a todo el continente americano con un nombre indígena. Este vocablo pertenece a la lengua kuna. Esta nación designa a su territorio como 'kuna yala' (tierra kuna) y 'Abya Yala' o 'tierra floreciente' designa un territorio mayor. El concepto Abya Yala no diferencia a USA y Canadá del resto, pues abarca a todo el hemisferio.

${ }^{29}$ Sobre la discusión del concepto ver Chacón (2005).

${ }^{30}$ Citado por Maldonado (2008). 


\section{Bibliografía}

Anderson, B (1983), Imagined Communities: Reflections on the Origins and Spread of Nationalism. Verso, London

Bengoa, J. (1985), Historia del Pueblo Mapuche Siglo XIX y XX. Editorial Interamericana Ltda., Santiago de Chile

Bolton, H. (1917), "The mission as a Frontier Institution in the SpanishAmerican Colonies”, American Historical Review Vol. 23 No. 1

Ídem (1932), “The Epic of Greater America.” American Historical Review Vol. XXXVIII No. 2

Calbucura, J. (2005), “Indoamérica en el Canto General de Pablo Neruda” in J. Godoy \& G. Perotti eds. El Canto General y América Latina en el siglo XXI. En el centenario de Pablo Neruda 1904 - 2004. Department of Education, Department of Spanish and Portuguese and Latin-American Institute; Stockholm University, Sweden.

Ídem (2008), “Legal Process of Abolition of Collective Property: The Mapuche Case;” in A. de Oliveira Ed. Decolonising Indigenous Rights. Routledge, London

Chacón, O. (2005), Teoría de los Derechos de los Pueblos Indígenas. Problemas y límites de los paradigmas políticos. UNAM / Universidad Autónoma de Chiapas, México.

Dietz, M. (1989), Patriotism in Ball, T. Farr \& R. Hanson (eds.) Political innovation and Conceptual Change. Cambridge University Press, Cambridge

Foucault, M. (2005), El sujeto y el poder, Ediciones Simbióticas http:// www.edicionessimbioticas.info/El-sujeto-y-el-poder. Visitada 100824

Gavilán, V (2002), “La República de Chile y los mapuches (1810-1881)” Actas del Primer Congreso Internacional de Historia Mapuche. Ñuke Mapuförlaget. Working Paper Series 28. www.mapuche.info/mapuint/ contreras070701.pdf. Visitada 100830

Guevara, T. (1913), Las Ultimas Familias y Costumbres Araucanas. Imprenta Litografía y Encuadernación Barcelona, Santiago de Chile.

Hernández, I. (1985), Derechos Humanos y Aborígenes. El Pueblo Mapuche. Ediciones Búsqueda, Buenos Aires.

Hidalgo, J. (1973), Algunas notas sobre los mapuches protohistóricos. Universidad Católica de Chile. Temuco. 
MacKendrick, P. (1957), "Roman colonization and the frontier hypothesis.” in The Frontier in Perspective, (eds.) W. Wyman, \& C. Kroeber. University of Wisconsin Press, Madison.

Maldonado, I. (2008), Los pueblos indígenas y las luchas por la liberación, la emancipación y la independencia, http://www.mapuche.info/ ?kat=8\&sida=662. Visitada 100824.

Mignolo, W. (2005), The Idea of Latin America. Wiley-Blackwell, London.

Ídem (2009), "La idea de América Latina (la derecha, la izquierda y la opción decolonial).” Crítica y Emancipación, (2): 251-276.

Överland O. (2000), “Old and new homelands, old and new mytologies. The creation of ethnic memory in the United Satates,” in in Runblom, H. (ed.) Migration and the Homeland. Fälth \& Hässler, Semedjebackem:

Rojo, G. (2005), Globalización e identidades nacionales y postnacionales. ¿De qué estamos hablando? Editorial Lom, Santiago de Chile.

Solís, L. (1981), “Alianzas Militares entre los Indios Araucanos y los Grupos de Indios de las Pampas: la Rebelión Araucana de 1867-1872 en Argentina y Chile.” Revista Nueva Historia 1: 3-49.

Turner, F. (1935), The Frontier in American History. Henry Holt \& Company, New York

Villoro, L. (1998), Estado plural, pluralidad de culturas. UNAM/Paidós, México.

Webb, W. (1986), The Great Frontier. University of Nebraska Press, Lincoln, Nebraska.

William, C. \& A. Smith (1983), The national construction of social space. Progress in Human Geography (7):4.

Yunque, A. (1956), La Conquista de las Pampas. Hachette, Buenos Aires.

Zeballos, E. 1961 [1890], Calvucura y la Dinastía de los Piedras. Hachette, Buenos Aires. 